Research, part of a Special Feature on Navigating Trade-Offs: Working for Conservation and Development Outcomes

\title{
Facilitating Cooperation During Times Of Chaos: Spontaneous Orders And Muddling Through In Malinau District, Indonesia
}

\author{
$\underline{E v a}$ Wollenberg $^{1}$, Ramses Iwan $^{1}, \underline{\text { Godwin Limberg }}^{1}, \underline{\text { Moira Moeliono }}^{1}, \underline{\text { Steve Rhee }}^{1}$, and Made Sudana ${ }^{1}$
}

\begin{abstract}
Adaptive management has become increasingly common where natural resource managers face complex and uncertain conditions. The collaboration required among managers and others to do adaptive management, however, is not always easy to achieve. We describe efforts to work with villagers and government officials in Malinau, East Kalimantan Indonesia, where a weak, uncertain institutional setting and complex shifting political landscape made formal cooperation among these groups for forest management problematic. Through successive trials, the team learned instead to work with and enhance a "spontaneous order" of cooperation using four tactics: (1) continuous physical presence, (2) regular contact with the people who advised and were close to major decision makers, (3) maintenance of multiple programs to fit the needs of different interest groups, and (4) hyperflexibility in resource allocation and schedules.
\end{abstract}

Key Words: Key words: adaptive collaborative management; Borneo; chaos; Kalimantan; spontaneous cooperation.

\section{INTRODUCTION}

Adaptive collaborative management (ACM) has become widely accepted as an approach for facilitating decisions about natural resources in complex, uncertain environments in which decision making among interest groups is required (Chess et al. 1998, Sinclair and Smith 1999, Wondolleck and Yaffee 2000, Buck et al. 2001, Colfer 2005). However, ACM assumes that cooperation among different groups can be guided in predictable ways. We suggest, to the contrary, that cooperation itself can be chaotic and uncertain, especially during times of political or organizational instability. How can ACM work under such conditions?

In this article we show that adaptive collaborative management in "chaotic" institutional contexts can benefit from the recognition and use of spontaneous cooperation among decision makers. Working with spontaneous cooperation requires special methods that bring particular challenges. We illustrate our case with examples from Malinau District, in East Kalimantan, Indonesia from 1998 to 2005, where our action research team used ACM to facilitate collaboration among communities and government to improve equity, incomes, and sustainable forest management, but did so during times of high political uncertainty and instability.

\section{LIMITS TO COLLABORATION}

Adaptive management of natural resources has emerged over the past $20 \mathrm{yr}$ as a way of coping with uncertainty, rapid change, and the complexity of whole systems (Holling 1978, Walters 1986, Poteete and Welch 2004). Adaptive management is decision making informed by a learning process: (1) setting management objectives; (2) implementing a decision to achieve the objectives; (3) observing outcomes and assessing against objectives; and (4) as necessary, adjusting the practice though a new decision (Lee 1993). Drawing on complexity and organizational theory, adaptive managers have tried to become more open to surprise, accident, and serendipity, and "welcome disorder positively" (Axelrod and Cohen 1999, Rosenhead 1998:6). They develop explicit learning strategies by seeking newly developing information that suggests new opportunities and emerging patterns of the organization and its environment (Senge 1990, 
Sanders 1998, Stacey 2003). Managers seek to have an active, iterative engagement with their environment and work in a flexible, responsive way that builds on their experience. Monitoring the environment is a key feature of the approach.

When different interest groups share a stake in a resource, such as forests, collaborative management can help meet these different groups' needs. Adaptive collaborative management (ACM) is thus adaptive management in which different interest groups engage in the cyclical learning process together (Buck et al. 2001, Colfer 2005). These approaches work best when strong communication, trust, coordination, and legitimate decision making and authority occur or can be built through improved relationships and institutions (Stacey 2003, Colfer 2005).

Unfortunately, under some circumstances, organizations find it difficult to build the relationships and institutions that support collaborative learning. Social unrest and political upheaval can result in a lack of capable institutions to mediate conflict or legitimize decisions. This, in turn, can reduce communication and trust among and within organizations. Organizations can have their own internal crises as well, due to a lack of capacity, leadership crisis, external pressures, or internal reform.

Ironically, ACM is intended to cope with complex external contexts, but has not addressed how to cope with complexity internal to decision making and management. How can decision makers cope with their own chaos and not just chaos in their environment?

In this article, we focus on this seeming contradiction to ask how collaborative learning is possible in unstable contexts and what methods are required to achieve it. We give special attention to cooperation among decision makers for its importance in supporting both collaborative learning and management.

\section{Chaos and spontaneous orders}

Chaos models provide one way of understanding how ACM practitioners can achieve cooperation under conditions of instability. Chaos theory predicts that when a system moves from equilibrium to instability, it passes through a state of bounded instability in which stability and instability operate at the same time, and cause and effect disappear (Stacey 2003). We propose that natural resource managers often face bounded instability during times of massive change, as they face a mix of controllable and uncontrollable conditions such as volatile markets, policy changes, social unrest, or natural catastrophes.

We have observed, however, that practitioners of ACM readily recognize chaos and bounded instability in their environment, but rarely address it in their own decision making. ACM can benefit from work in organizational learning theory that acknowledges internal chaos and identifies its predictabilities (Senge 1990, Stacey 2003).

According to organizational learning theory, during bounded instability, behavior has a spontaneous, self-organized emergent pattern that is irregular and highly complex (Stacey 2003). The emergent pattern often occurs at new scales, e.g., smaller or larger groups, longer or shorter decision-making cycles. The pattern is itself subject to vary with small changes in the environment and it is impossible to know the long-term future.

Hot groups are an example of such an emergent pattern and have been prescribed by some as a way for organizations to be more responsive to rapidly changing environments (Lipman-Blumen and Leavitt 1999). Hot groups do not constitute a structural unit in an organization. People come together voluntarily and spontaneously because of common interests. The groups organize themselves quickly, are flexible, and have high motivation and capacity for innovation.

When bounded instability occurs among ACM decision makers, cooperation among them can thus be viewed as a self-organized, spontaneous, emergent pattern that is likely to take place at scales different from what ordinary, formal decision making would suggest. Scale refers here to different levels or degrees of social organization or decision making. The emergent, spontaneous order of cooperation cannot be guided by a single organization or hierarchical entity. Instead, people pursue their own ends and mutually adjust to each other to form cooperative arrangements across the boundaries of their usual activities. In the remainder of the paper, we use the terms spontaneous orders of cooperation, spontaneous cooperation, or orders interchangeably for ease of reference. 
Spontaneous orders of cooperation can have advantages over designed cooperation. Competition can exist among parties and can promote more rigorous outcomes as it does in the way selforganized practice of science, free markets, or democracy (diZerega 2000). Spontaneous orders of cooperation can also incorporate more complex relationships and information as they are not limited by people's cognitive and organizational skills (diZerega 2000).

One of the disadvantages, however, is that spontaneous orders tend to be dissipative structures (Nicolis and Prigogine 1989) that require "great effort to retain its structure and relatively little to change it," in contrast to the equilibrium structure that "requires no effort to retain its structure and great effort to change it." (Stacey 2003:226). Staying in this state is therefore not efficient, as it requires continuous inputs of energy, attention, and information (Rosenhead 1998, Stacey 2003). However, managers can benefit from the innovation and opportunities they yield.

Chaos models therefore suggest that it may be imprudent to engineer formal cooperation during times of instability. Rather, people should try to work with spontaneous orders of cooperation as they emerge. By better understanding spontaneous cooperation, certain elements of what appears to be chaos become more predictable. Efforts should be directed at identifying the more predictable opportunities for cooperation and being responsive to how those opportunities change. It should be recognized that trying to maintain or manage spontaneous orders of cooperation may be expensive due to the requirement for continuous inputs and difficulty of predicting how the orders will evolve.

\section{MALINAU AND THE POLICY TRANSITION}

The district of Malinau is in the endangered "heart of Borneo," where broad expanses of Dipterocarp forest constitute one of the last large forest areas of Southeast Asia (Fig. 1). Nearly all of Malinau is state forestland. Most of the district's 40,000 inhabitants practice swidden agriculture and hunting and gathering from the forest. They include more than 20 ethnic groups, including the largest group of Punan hunter-gatherers in Borneo. Most accessible lowland forests are now degraded as a result of logging and extensive swidden cultivation.
The Malinau River watershed is the most densely populated area of the district, and the most developed. About 6,673 people lived in the 500,000 ha watershed in 2003 (Malinau Voting Census 2003).

After $32 \mathrm{yr}$ of repressive authoritarian rule, the fall of the Suharto regime in May 1998 initiated a surge of dramatic political reforms and uncertainty throughout Indonesia. Policy reforms gave more control to district governments, including the right to reap more benefits from local economic activities and for people to choose their own representatives. Reforms decreased government censorship and intimidation and allowed people to protest and address conflicts more openly (Wulan et al. 2004). Widespread euphoria about the possibilities for more democracy resulted, but so did widespread confusion, as most institutions were not yet ready for the new rights and responsibilities thrust upon them.

Forest-rich parts of Indonesia, such as Malinau, experienced enormous instability during these reforms. Local governments suddenly had opportunities to capture timber profits that had previously gone to the central government and concession holders. The districts immediately mobilized small-scale timber harvesting in their areas (Barr et al. 2001, Limberg et al. 2004). From April 2000 to August 2001, Malinau District issued 46 cutting permits granting access to more than 60,000 ha in Malinau. At the same time, local communities felt empowered to make claims to forestland and to demand compensation for damages. Confusion about the classification of land functions and conflict over claims to forestland increased exponentially, with more than 69 cases of conflict occurring between 2000 and 2002, compared to only 8 during the Soeharto period (Sudana 2004:2). The central government made numerous attempts to stop logging. With the passage of a regulation in 2002, the Ministry of Forestry made the district cutting permits illegal.

Decentralization also led to the creation of new districts in Indonesia. Malinau formed in October 1999 as a split-off from the District of Bulungan. The district pieced together its staff largely from local teachers, educated villagers, and lower level administrators. Malinau's administrative capacities were thus extremely weak. Most officials were poorly informed about the policy, and many lacked experience. For example, the district forestry 
Fig. 1. District of Malinau, Indonesian Borneo.

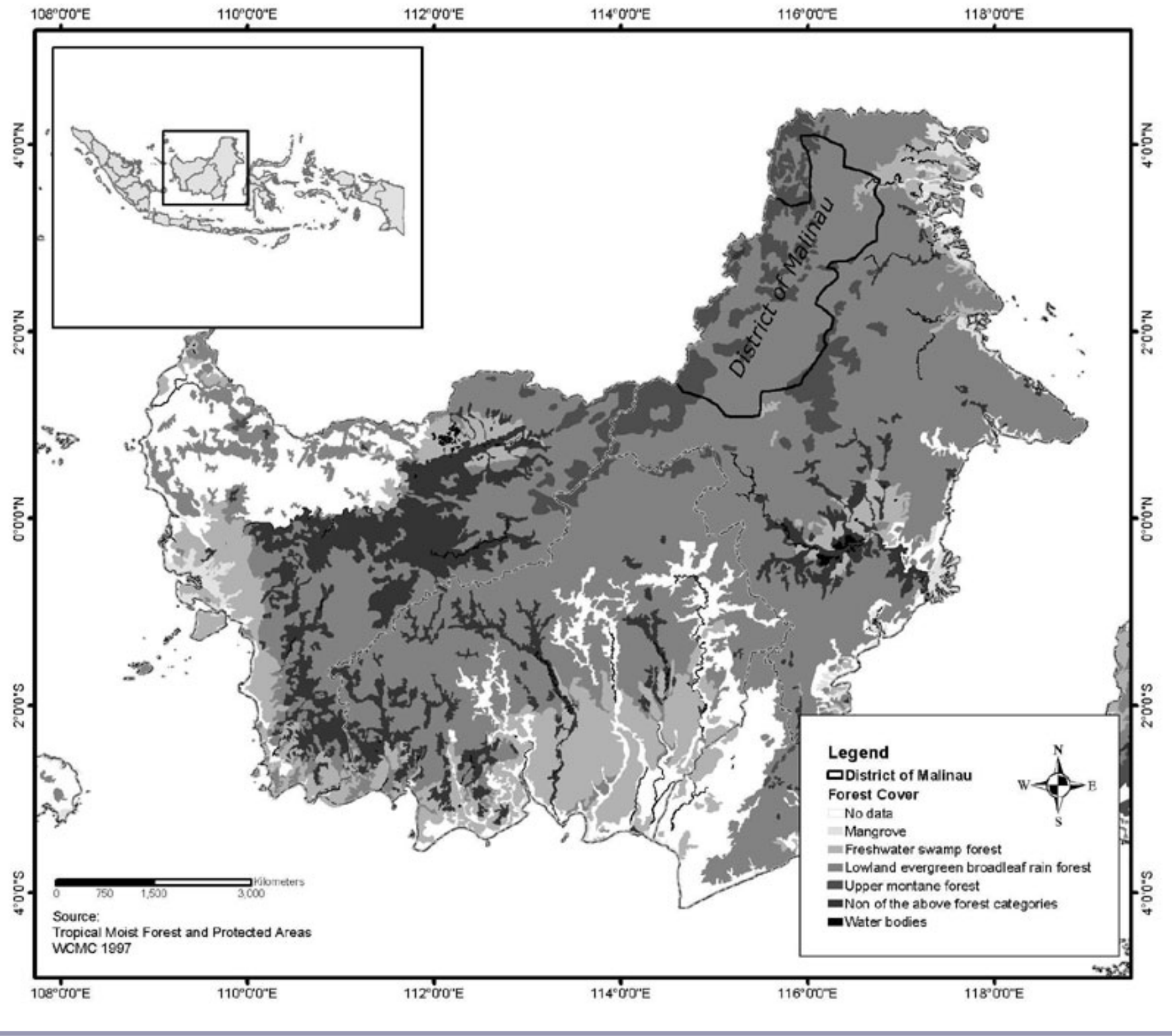

service, land registering agency, and coordinating agency could not agree about the ownership status of forestland in the district or the legal basis for allocating it.

Because reforms created a mandate for more populist politics, some officials made exorbitant promises to communities. Communities, in turn, made exorbitant demands and happily exercised their right to disregard government authority.
Communities and officials tried to work out deals with each other and with the timber companies that would best serve their interests. There was no model or standard that people could follow to gauge what was "right" behavior in the new system. Everything was fluid and up for grabs.

The turmoil of the transition lessened in 2003 as small-scale timber licenses become illegal and officials settled into their roles. However, enormous 
uncertainties persisted. In 2006, district government and local people still contested their roles in forest management and how the forest should be used.

\section{Facilitating collaboration}

In Malinau, policy reforms enabled ethnic divides and competition across all sectors of society to give some people new influence, while marginalizing others, especially communities in forest areas. The Center for International Forestry Research (CIFOR) sought to assist forest communities to increase their access and control over forest benefits and decisions. This aim included trying to improve income opportunities for communities, and rights to forest and land and management.

We used adaptive collaborative management (ACM) with local partners to determine interventions. As researchers used to facilitating information flows, our interventions focused on improving communication, joint learning, conflict management and deliberation. We facilitated relationships among communities and between communities and government. Activities focused on the 27 forest villages in a single watershed near Malinau in which forest management and income opportunities were especially volatile. CIFOR was committed to working in this part Malinau as a longterm research site. Individuals from the communities and government participated as partners and beneficiaries.

Our core team, i.e., the "CIFOR team," drove the adaptive learning process by periodically reflecting upon our activities and revising our strategy for interventions. We monitored our impact through routine surveys of villages every 3-6 mo, as well as through evaluations of major activities. Informal observation of experiences was also important. The team of 5-7 members had expertise in community outreach, forest conservation, community-based management, mapping, anthropology, and agriculture, with long-term experience in Kalimantan. Three members were from local villages.

Initiated in 1998, our work had five components. Each component served as a learning cycle that informed the next: villagers'

1. Village surveys and monitoring to understand local concerns and conditions

We conducted surveys in 1998 to orient ourselves to design locally relevant programs. We found it useful to continue visits to villages to monitor reform developments and our impact. Villagers or government officials sometimes participated. Monitoring included observations of the forest, as well as economic, political, and social conditions.

2. Participatory mapping and village agreements In response to villagers' interests villagers' to demarcate their customary lands, we mediated conflicts over village boundaries and facilitated mapping among villages from January to July 2000. The team did not complete the mapping due to the difficulty of maintaining boundary agreements and lack of endorsement from the district government (Anau et al. 2002). The reform period was at its most chaotic during this time. The experience indicated that Malinau lacked institutions to secure legal recognition of claims to land. To address this gap, we worked with local people and officials to develop principles to develop stable agreements and manage conflict.

3. Legal awareness and policy dialog

Following the need for improved institutions, starting in 2001 we facilitated awareness building and policy dialogue among government officials and communities about multistakeholder land use planning, public participation, representation, customary rights, and the use of public forests as sources of village revenue. We shared information on these topics through informal discussions, policy briefs, newsletters, sharing of the regulations and laws, workshops, and cross visits.

4. Community participation in district land use planning

In 2001, Malinau started preparation of a land use plan, rencana tata ruang. We saw this as a practical opportunity to enable communities to have more influence over forest decisions and access to forestland. We worked to link village and district-level land use decision making. Relationships with the district were cool. Officials distrusted our motives, as our aim was to empower communities. Although we established an MOU, several committees, and a workplan with the district, the formality of these measures only distanced us further. 
Few villagers knew that the district was developing a land use plan, so we helped them analyze their land use priorities and report these to the district. Officials and the technical consultants did not value the input from villagers. We had difficulty coordinating with officials, as their schedules changed frequently at the last minute. The interest in collaboration of the more powerful community and government groups declined when they realized there was no money available, whereas more marginalized groups increasingly sought us out.

It was during this time that we first recognized the importance of spontaneous cooperation. Watching the plethora of deal making around us, we realized that officials and villagers were able to cooperate easily enough with one another to exploit timber, and found this more interesting than our efforts to support formal land use planning. To increase our relevance to communities and the government, we decided to "go with the flow" to facilitate villages in identifying forest-based enterprise options that could be supported by government. We took a more flexible, informal approach and worked with fewer villages to give them more individualized attention.

5. Village economic development and land use In 2002 we began facilitating the development of new economic uses of forest in four villages. We developed a congenial collaboration with the newly formed District Village Empowerment Service (PMD), which shared similar values of community development and had few vested interests in timber. Unfortunately, PMD was not a very powerful agency, and again, villagers saw little responsiveness to their requests for enhancing gaharu, rattan, or rubber production in their areas.

In this final phase, we worked more directly with communities again, as collaboration with the district had created more of a burden than a help. With some facilitation, villagers did inventories of their community forests to assess the potential for their preferred land use plan and drew up future scenarios, management plans, and work plans. With officials, we relied on coincidental convergences of interests to guide collaboration rather than trying to plan. For example, in 2004 we sponsored a provincial research and development office to train local people how to inoculate Aquilaria trees with a fungus to produce gaharu, a fragrant wood worth up to USD $1,000 / \mathrm{kg}$. One of the government officials at the workshop suggested to the district leader that the local government initiate a gaharu planting program. Six months later the district launched their "Movement for planting one million gaharu trees." As the inoculation carried out during the training yielded positive results, communities purchased and planted hundreds of gaharu seedlings in mid-2005.

\section{Facilitating by muddling through}

Our capacity to be flexible in our facilitation strategy was key to working with spontaneous cooperation. We made adjustments by "muddling through" (Lindblom 1959), using available limited information and evaluating only a few, incrementally different alternatives at a time. Muddling through is thought to yield positive outcomes when the outcomes of decisions are hard to predict, and so the risks of radical change are high (Bendor 1995). Muddling through is also a practical way to make sense of the messiness of complexity (Bernstein and Fortun 1998). We suggest such muddling is more realistic than the more comprehensive and routine information requirements suggested by more formal scientific adaptive management practice or participatory action research.

Each cycle of activity evolved in the context of work that preceded it and reflected our own deeper understanding and embeddedness in Malinau. Over time, we found that small, but incrementally significant achievements occurred because of fortuitous circumstances, e.g., a chance meeting with an influential person, a coincidence of interests among key actors, an unexpected event providing an opportunity for influence. An issue raised coincidentally with the right person at the right time resulted in action. These coincidences became as important to achieving our objectives as our purposeful activities. We learned to increase the possibility for these opportunities through four tactics. 
The most important tactic was to have staff physically present in the area and interact often with different groups. By "being around," we increased our opportunities for informal interactions with people, which was more conducive to building trust and relationships. We also increased the likelihood of chance meetings with the gatekeepers. These were people with authority, influence, and control; the movers and shakers who could short-cut the bureaucracy and get things done. These included the district leader and agency heads who, under formal circumstances, would have been harder to meet and were less communicative. Other people were able to find us more easily to provide information they thought we needed to know, including invitations to events, news of cancelled plans, their understanding of hidden motives, or an alternative interpretation of the discourse surrounding an issue. Opportunities for spontaneous cooperation with more marginalized groups also increased, as they became more confident in knowing where to find us.

The second tactic was to work informally and build relationships with the support network of the gatekeepers. The support network included people who advised or influenced the gatekeepers, people who knew and organized schedules, and people who had the latest inside information about decisions. From these interactions we were able to learn the timing of ad hoc gatherings and events and the interests that motivated different groups to participate in different events. These factors were the key determinants of being able to engage with spontaneous cooperation in Malinau.

The third tactic was to maintain multiple strands of activities with different stakeholders. We found it easier to have separate programs of work among communities and local government, rather than one joint program. In this way, the priorities of different groups could be met, there was less need for coordination, and one group did not depend on another to take action. For example, one village was more concerned with developing opportunities for commercial timber production and harvesting, whereas another wanted to stop logging and promote ecotourism. We worked with each independently, while also facilitating district-level officials to discuss priorities for the district land use plan. Nevertheless, we continued to create opportunities for groups to meet.
The fourth tactic was to maintain hyperflexibility in our schedule and resources. We learned to be ready to reorganize our plans and reallocate staff at the last minute to take advantage of sudden opportunities, as well as routinely adjust our strategy. Maintaining this flexibility was the most difficult, costly, and frustrating aspect of facilitation. It required adequate contingency funds to cover changing travel or workshop plans. However, it also reaped significant gains at times, enabling us to have more frequent engagement with policy makers and catch timely opportunities for having policy input. Being flexible meant accepting inefficiencies, hence the aptness of the muddling metaphor. We explicitly acknowledged the risks and inefficiencies that team members encountered and tried to provide them with extra support to cope with it. Ultimately, there were limits to the risk and inefficiency that we could tolerate, and we needed to regularly evaluate overall gains or losses.

Our most successful efforts at institutionalization were in building capacity of individuals and in working with like-minded agencies. In the spirit of working with spontaneous cooperation, we felt that it would be unwise to invest in more intensive institutionalization. We do not expect the meetings we have facilitated to be continued in their current form, but we do expect that the types of relationships and activities in which communities and government engage will be affected. In this way, we may have had a small impact on future collaborative learning.

\section{Outcomes}

Our muddling efforts had some outcomes and impacts according to evaluations conducted in 2003 and 2006 by people external to our program. Although there were few hard, visible changes in forest benefits and influence over decisions in communities, the intermediate outcomes of building collaboration and new awareness were significant. According to a 2003 survey of 52 villagers, most respondents felt that the program:

- Expanded our thinking, thereby helping us to understand conditions elsewhere, increasing our information and experience, and providing feedback about our situation; 
- Helped our community advance and develop, and provided input to community through advice and explanations;

- Improved relationships among villages, reduced conflicts, and helped with boundaries;

- Helped to bridge communities and government; and

- Improved awareness about forest conservation.

Villagers also observed that the program created little tangible economic benefits for communities and were frustrated that CIFOR did not take a more active role in technical forest management or income generation. People were most pleased with the gaharu inoculation activity for its direct economic value. One village also successfully protected its forest with help from the program. Some officials, particularly in the district forestry department, were predictably negative about our work, as it exposed and discouraged the uncontrolled nature of logging in Malinau.

Generally, less influential villagers and government organizations were more positive about the impacts of our work. The mix of views and interests in collaboration reflected the reality of the values of the different groups involved. In a project intended to empower a marginalized group, it may be difficult to prevent other groups from feeling threatened. Facilitating collaboration requires specific strategies for dealing with each group. It also means being prepared to have some groups try to undermine your goals and handle conflict with authorities.

Over time, as the district established itself and CIFOR became a better known and trusted entity, responses became even more positive. In the 2006 survey of 65 people, i.e., 28 villagers from 13 villages and 37 government officials, $80 \%$ of the respondents agreed that the results of CIFOR's research, including non ACM projects, were useful for improving their knowledge about forests and conservation. Nearly all, i.e., 97\%, said it was important for CIFOR to continue working in Malinau.

The responses suggest that facilitating cooperation and shared learning are valued, despite their intangibility. Like Castellanet and Jordan (2002), we believe that the biggest accomplishment of this type of action research is change in capacities and attitudes. Getting different groups to talk freely with each other about their needs is already a big achievement (Hagmann 1999). We hope that over time, these small changes will support concrete action.

Working with spontaneous cooperation made the chaotic environment more predictable and manageable. Although we might have been more effective in a more stable environment, we did not have that choice due to institutional commitments of CIFOR to Malinau. We believe that many decision makers find themselves in similar situations in which they have to cope with chaos, whether they want to or not.

Although working in a less chaotic environment would have been more efficient, working in chaotic environments may have other advantages. The relationships formed under often dramatic circumstances built deeper levels of trust than otherwise possible in a short time. People were more receptive to innovative ideas and social arrangements. Our goal of empowering marginal groups might have been less successful working with more entrenched policies and social structures.

\section{CONCLUSION}

Existing models of adaptive collaborative management or other simple platforms for collaboration (Hemmati 2002) are unlikely to work in places like Malinau, at least not with socially just and long-term outcomes. These approaches presume communication and trust exist or can be built easily, and that clear institutions for deliberation, agreements, checks and balances, and managing conflict are in place. In Malinau, and elsewhere with weakly developed civil society or states with low capacities, these conditions do not exist. The high transaction costs of collaboration and possibilities for co-optation or unsustainability are too high.

The alternative, as chaos theory helps to show, is to learn to work with spontaneous orders of cooperation. Working with spontaneous cooperation requires a more embedded and informal approach that includes being physically present in an area; maintaining close relations with the people who support gatekeepers; developing programs for multiple interest groups; and being hyperflexible. This approach identifies and builds on predictabilities that exist in chaotic systems. 
This form of adaptive management requires accepting a "muddling through" attitude and coping with resulting risk and inefficiencies. Learning opportunities need to be built into schedules explicitly, with generous amounts of time allowed. Reflection processes need to be creative and efficient so as to maintain their appeal. Facilitation strategies need to be flexible enough to respond to changing opportunities, yet not change so often that other groups do not understand the purpose or direction of the work. In Malinau, adjusting strategies about once a year seemed to work. These changes were incremental and built iteratively upon earlier strategies. Adjustment does not mean abrupt departure from objectives and established processes. Facilitators need to allow enough time to really test and evaluate their strategies before they change them.

The strength of the informal, muddling approach to adaptive management is that it can increase the relevance of facilitation to local circumstances. Information is more accurate, in-depth, and comprehensive, especially in terms of hearing different perspectives from different groups. Facilitation more closely mirrors how local policies are made and therefore enables the facilitators to take advantage of different waves of opportunity to initiate new cycles of work and to engage different groups at times of maximum impact. It is more possible to carve out the space to work independently, as we did with villagers on their proposals to government or village land use plans, or to monitor village conditions with officials in the Empowerment Service without battling the resistance of other offices. Officials are less likely to co-opt the agenda. Social relationships are more embedded.

The weakness of this approach is that it entails risks and inefficiencies. As chaos theory suggests for dissipative structures, spontaneous cooperation requires continuous input to be maintained. The frustrations and constant reallocation of resources associated with hyperflexibility can impose severe costs. The approach requires a team that can be tolerant of such demands and have the forbearance to sustain their own motivation. When working more informally, it can be hard to have the same level of transparency and credibility acquired through more formal cooperation. Special efforts need to be made to get the endorsements of gatekeepers and to share information intensively.
From a research perspective, it is more difficult to collect consistent information for comparisons.

Despite the weaknesses, such approaches may be the best choice for facilitators in unstable times. Muddling is often the only practical option. The facilitator needs to judge whether enough incremental gains are being made in a given period to warrant the effort and the opportunity costs of the efforts. Sometimes it will be better to wait for more stable conditions, although there can be less room for innovation or building relationships during such times.

The selection of methods in any site is itself an iterative and adaptive "muddling" process. We do not suggest that the approach we took in Malinau is necessarily the best to take elsewhere. These decisions are highly dependent on resources available to the facilitators, their own capacities, and the environment in which they are working. We think that these sorts of approaches contribute to a more democratic and feasible way of facilitating change. Our goal has not been to directly facilitate collaboration, rather it has been to create an enabling environment for accommodating interests and their coordination, especially of weaker groups. This is a messy muddling process, but it is also a reality of political change.

Responses to this article can be read online at: http://www.ecologyandsociety.org/voll2/iss 1/art3/responses/

\section{Acknowledgments:}

We thank our partners that collaborated in ACM program in Malinau, including the Bulungan and Malinau district and sub-district offices, including the Agency for Planning, Forestry Service, Community Empowerment Service, Agricultural Service, Economy Service, Law Unit, INHUTANI II, Meranti Sakti (another local timber concession), and the provincial Forest Service. We have also collaborated with Plasma, SHK-Kaltim, PPSDAK, Padi, LPMA, Phemdal, WWF, P-5-Universitas Mataram, the University of Victoria (Canada), Wageningen University and Yale University in various components of the work. We also thank the three reviewers who provided thoughtful comments that helped us to improve the article. 


\section{LITERATURE CITED}

Anau, N., R. Iwan, M. van Heist, G. Limberg, M. Sudana, and E. Wollenberg. 2002. Negotiating more than boundaries: conflict, power, and agreement building in the demarcation of village borders in Malinau. Pages 131-156 in CIFOR. Forest, science and sustainability: the Bulungan Model Forest. ITTO project PD 12/97 Rev.1 (F): Technical Report Phase 1, 1997-2001. CIFOR, Bogor, Indonesia.

Axelrod, R., and M. D. Cohen. 1999. Harnessing complexity: organizational implications of a scientific frontier. The Free Press, New York, New York, USA.

Barr, C., E. Wollenberg, G. Limberg, N. Anau, R. Iwan, M. Sudana, M. Moeliono, and T. Djogo. 2001. The impacts of decentralization on forests and forest-dependent communities in Kabupaten Malinau, East Kalimantan. CIFOR, Bogor, Indonesia.

Bendor, J. 1995. A model of muddling through. American Political Science Review 89(4):819-840.

Bernstein, H. J., and M. Fortun. 1998. Muddling through: pursuing science and truth in the twentyfirst century. Counterpoint Press, New York, New York, USA.

Buck, L. E., E. Wollenberg, and D. Edmunds. 2001. Social learning in collaborative management of community forests: lessons from the field. Pages 21-44 in E. Wollenberg, D. Edmunds, L. Buck, J. Fox, and S. Brodt, editors. Social learning in community forests. CIFOR, Bogor, Indonesia.

Castellanet C., and C. F. Jordan. 2002. Participatory action research in natural resource management: a critique of the method based on five years' experience in the Transamazonica Region of Brazil. Taylor and Francis, Ann Arbor, Michigan, USA.

Chess, C., T. Dietz, and M. Shannon. 1998. Who should deliberate what? Human Ecology Review 5 (1):45-48.

Colfer, C. J. P., editor. 2005. The complex forest: communities, uncertainty and adaptive collaborative management. Resource for the Future/CIFOR, Washington, D.C., USA.
diZerega, G. 2000. Persuasion, power and polity: a theory of democratic self-organization. Hampton, Cresskill, New Jersey, USA.

Hagman, J. 1999. J. 1999. Learning together for change. Margraf Verlag, Werkershein, Germany.

Hemmati, M. 2002. Multi-stakeholder processes for governance and sustainability: beyond deadlock and conflict. Earthscan, London, UK.

Holling, C. S. 1978. Adaptive environmental assessment and management. John Wiley and Sons, New York, New York, USA.

Lee, K. N. 1993. Compass and gyroscope: integrating science and politics for the environment. Island Press, Washington, D.C., USA.

Limberg, G., R. Iwan, M. Moeliono, M. Sudana, and E. Wollenberg. 2004. It's not fair, where is our share? The implications of small-scale logging on communities' access to forests in Indonesia. Paper presented at the Meeting of the International Association for the Study of Common Property, 913 August 2004, Oaxaca, Mexico and at the International Conference on Land and Resource Tenure, Questioning the Answers, 11-13 October 2004, Jakarta, Indonesia.

Lindblom, C. E. 1959. The science of "muddling through." Public Administration Review 19 (2):79-88.

Lipman-Blumen, J., and H. Leavitt. 1999. Hot groups: seeding them, feeding them, and using them to ignite your organization. Oxford University Press, New York, New York, USA.

Malinau Voting Census. 2003. Malinau voting census data. Regional Government of Malinau District, East Kalimantan Province, Indonesia.

Nicolis, G., and I. Prigogine. 1989. Exploring complexity: an introduction.W. H. Freeman, New York, New York, USA.

Poteete, A. R., and D. Welch. 2004. Institutional development in the face of complexity: developing rules for managing forest resources. Human Ecology 32(3):279-311.

Rosenhead, J. 1998. Complexity theory and management practice. Available online at: http://w 
ww.human-nature.com/science-as-culture/rosenhead. html.

Sanders, T. I. 1998. Strategic thinking and the new science: planning in the midst of chaos, complexity, and change. The Free Press, New York, New York, USA.

Senge, P. M. 1990. The fifth discipline: the art and practice of the learning organization. Currency Doubleday, New York, New York, USA.

Sinclair, A. J., and D. L. Smith. 1999. The model forest program in Canada: building consensus on sustainable forest management? Society and Natural Resources 12:121-138.

Stacey, R. D. 2003. Strategic management and organisational dynamics: the challenge of complexity. Fourth edition. Financial Times/ Pearson Education, Edinburgh, UK.

Sudana, M., R. Iwan, G. Limberg, M. Moeliono, and E. Wollenberg. 2004. Winners take all: understanding forest conflict in the era of decentralization in Indonesia. Paper presented at the Meeting of the International Association for the Study of Common Property, 9-13 August 2004, Oaxaca, Mexico and at the International Conference on Land and Resource Tenure, Questioning the Answers, 11-13 October 2004, Jakarta, Indonesia.

Walters, C. 1986. Adaptive management of renewable resources. MacMillan, New York, New York, USA.

Wondolleck, J. M., and S. L. Yaffee. 2000. Making collaboration work: lessons from innovation in natural resource management. Island Press, Washington D.C., USA.

Wulan, Y. C., Y. Yasmi, C. Purba, and E. Wollenberg. 2004. Analisa konflik sektor kehutanan di Indonesia 1997-2003. CIFOR, Bogor Indonesia. 